\title{
Quais são os efeitos do envelhecimento populacional nos sistemas previdenciários de Brasil, Espanha e França?
}

\author{
Lucas Campos Amaro* \\ Luís Eduardo Afonso ${ }^{\star \star}$
}

O objetivo do trabalho é analisar os impactos do envelhecimento populacional sobre os regimes previdenciários de repartição de três países: Brasil, Espanha e França. Os benefícios e as contribuições são calculados com base nas regras atuais e nas projeções populacionais por sexo e grupo etário, até 2100. De 2016 a 2100, o número de benefícios programáveis nos três países deverá aumentar 235\%, 54\% e 73\%, respectivamente. Em 2050, ceteris paribus, o déficit brasileiro será de USD 188 bilhões, alcançando USD 260 bilhões em 2100. Para França e Espanha, os valores corresponderão a USD 134 bilhões e USD 92 bilhões. Em 2100 o déficit per capita espanhol será o mais elevado: USD 7.200, contra USD 5.400 para a França e USD 3.300 para o Brasil. São feitos ainda dois exercícios adicionais. 0 primeiro é o cálculo da alíquota de contribuição necessária de equilíbrio. Em 2016 a alíquota já deveria ser de 40\% para o Brasil, $23 \%$ para a França e $32 \%$ para a Espanha. Em 2050, se nada for feito, a alíquota brasileira ultrapassará absurdos $100 \%$ e, em 2100, superará irreais 160\%. 0 segundo exercício foi o cálculo do benefício médio de equilíbrio. Para a Espanha, haveria redução de USD 884 mensais para USD 372 em 2050. Para o Brasil, o atual benefício de equilíbrio de USD 248 seria reduzido em 2050 para USD 98. 0 decréscimo no Brasil (60\%) é praticamente igual ao da Espanha (58\%). Os resultados proporcionam evidências sobre a necessidade de reformas previdenciárias devido ao envelhecimento.

Palavras-chave: Envelhecimento. Previdência social. Regime de repartição.

\footnotetext{
*Chubb Seguros Brasil S.A., São Paulo-SP, Brasil (lucascamposamaro@gmail.com; http://orcid.org/0000-0002-3861-7415). ** Universidade de São Paulo (USP), São Paulo-SP, Brasil (lafonso@usp.br; http://orcid.org/0000-0003-4639-8299).
} 


\section{Introdução}

Na maior parte dos países, os sistemas previdenciários têm sido colocados em xeque. Gastos crescentes, dificuldades para encontrar formas de financiamento que não onerem excessivamente nenhum grupo ou geração e a forte reação da sociedade às proposições de reformas são alguns dos elementos comuns a este quadro. Na origem deste quadro está o processo de envelhecimento populacional, resultante das transições epidemiológica e demográfica (UHLENBERG, 2005).

Ao final desta segunda transição, um dos resultados é o aumento da proporção de idosos na população, o que implica, ceteris paribus, maior dispêndio público em áreas como a saúde. Mas é na previdência social que os reflexos são mais nítidos.

Os sistemas previdenciários organizados sob a forma de regimes de repartição são constituídos com base na solidariedade intergeracional, sendo esta compulsória (por meio do governo) devido às externalidades significativas e às imperfeições de mercado (FELDSTEIN; LIEBMAN, 2002). As coortes nas idades ativas contribuem com os recursos utilizados para pagamento dos benefícios previdenciários dos idosos. Tendo em vista a natureza das transferências intergeracionais efetuadas, é esperado que o processo de envelhecimento leve a um aumento das despesas com o pagamento de benefícios, sem que haja contrapartida nas contribuições, ou mesmo com a redução destas.

Este processo não é recente (PAILLAT, 1976) e, de forma geral, levará a maior pressão sobre os gastos, podendo conduzir a uma grave crise fiscal (MILLER; CASTANHEIRA, 2013). Ou seja, coloca-se uma ameaça à sustentabilidade dos sistemas previdenciários. Este conceito é empregado, com base nos termos de Mattil (2006) e Richards, Hurd e Clacher (2017), como a capacidade de financiar os benefícios previdenciários atuais e futuros do sistema previdenciário, sem exigir um volume de recursos acima do que seria considerado razoável. Ou seja, é uma visão predominantemente fiscal.

Por este motivo, um contingente expressivo de países vem realizando sustainability-enhancing reforms, conforme caracterizado por Carone et al. (2016), em função dos efeitos do envelhecimento. Isso ocorre tanto nos países que já se encontram em fases mais adiantadas da transição demográfica, quanto naqueles cujos sistemas previdenciários ap resentam inconsistências de desenho (pension design), que são exacerbadas pelo envelhecimento.

Estas reformas, de modo geral, podem ser realizadas de diversas maneiras: pela redução do dispêndio agregado com benefícios (decréscimo do valor unitário e/ou do número de beneficiários, a partir de mudanças nas condições de exigibilidade); por maior sacrifício das coortes trabalhadoras com o aumento de alíquotas contributivas; ou pela combinação de ambas as possibilidades.

Entretanto, não é uma tarefa imediata isolar os impactos do processo de envelhecimento populacional. Conforme aponta Schmähl (1990), este tópico é bastante complexo porque há intrincada relação entre as variáveis econômicas e demográficas que influenciam o equilíbrio dos sistemas previdenciários, de tal forma que pode ser difícil identificar e 
isolar efeitos tipicamente correlacionados entre si. Acosta-Ormaechea, Espinosa-Vega e Wachs (2017) complementam ainda que a demora para execução de reformas previdenciárias e a defasagem para que as medidas adotadas façam efeito agravam ainda mais este preocupante quadro.

Com base neste cenário, formula-se a seguinte questão: quais os impactos do enveIhecimento populacional sobre os sistemas previdenciários de Brasil, Espanha e França? Estes três países adotam em seu sistema básico o regime de repartição, que deve ser mais afetado pelas alterações demográficas. Para responder a esta pergunta, são projetadas as mudanças nas receitas de contribuições e nos gastos com benefícios programáveis, exclusivamente oriundos do processo de envelhecimento das nações selecionadas, até 2100. Na sequência, com base na experiência internacional de reformas previdenciárias, são feitas duas extensões aos resultados iniciais: o cálculo da alíquota necessária para que haja equilíbrio entre receitas e despesas, a cada ano; e o cálculo do benefício médio, que deveria vigorar para que os sistemas mantivessem o equilíbrio entre receitas e despesas previdenciárias.

A seguir é abordada a relação entre envelhecimento e regimes previdenciários de repartição. Posteriormente apresentam-se os procedimentos metodológicos utilizados e uma concisa descrição dos sistemas previdenciários dos três países. Por fim são discutidos os resultados e tecidas as conclusões.

\section{Envelhecimento e previdência social: uma delicada relação}

\section{Alguns elementos conceituais}

De forma geral, sistemas previdenciários desempenham duas funções primárias: suavizar intertemporalmente o consumo e funcionar como um mecanismo de seguro. No primeiro caso o objetivo é reduzir o consumo nos anos produtivos para realocá-lo para o período de inatividade. A segunda função é decorrente da incerteza individual sobre a duração da vida (e também sobre a ocorrência de eventos que afetem a capacidade de geração de renda). Como é bem descrito na literatura, riscos de longevidade e/ou morte precoce podem ser gerenciados mais adequadamente de forma coletiva do que individual, por meio do mutualismo, o qual é institucionalizado pelo seguro, seja privado, seja social, como é o caso da previdência (VAUGHAN; VAUGHAN, 2008). Além disso, duas outras funções são também relevantes: reduzir a desigualdade e diminuir a pobreza entre os idosos, por meio de transferências inter e intrageracionais (BARR; DIAMOND, 2006). Adicionalmente, deve-se mencionar que sistemas previdenciários devem ser avaliados no tocante ao cumprimento de seus objetivos, com relação aos objetivos de adequação e sustentabilidade (BROWN, 2008). Enquanto, no primeiro caso, o foco é individual, no segundo, está ligado à capacidade agregada de cumprir no longo prazo os benefícios previamente acordados no pacto social. Este é um tema da maior importância na literatura previdenciária (MATTIL, 2006). 
A compulsoriedade das contribuições previdenciárias é justificada pela existência de externalidades significativas e por imperfeições de mercado. Entre as causas mais comuns, estão: a miopia do indivíduo sobre o seu ciclo de vida e necessidades futuras, pois muitas pessoas não se planejariam adequadamente para os anos de aposentadoria, o que poderia resultar em sua pobreza ou na redução extrema de seu consumo nos anos de inatividade; evitar o risco moral por parte de indivíduos que sabem que há altruísmo na sociedade e que esta lhe garantirá recursos futuros, mesmo que nada tenham contribuído durante os anos produtivos; e o desejo de redistribuir recursos com base na renda dos anos produtivos do indivíduo em vez da renda de um ano em particular (FELDSTEIN; LIEBMAN, 2002).

Grosso modo, há duas formas de organização de regimes previdenciários: fully-funded (regime de capitalização) e pay-as-you-go (regime de repartição). No primeiro caso, durante a vida ativa, o trabalhador poupa parte de sua renda laboral, acumulando recursos para a aposentadoria. Estes são capitalizados com uma determinada taxa de juros $r$, que corresponde à taxa de retorno do regime de capitalização. Ao final da vida ativa, o montante e o rendimento acumulados são convertidos em benefícios de aposentadoria, com base em preceitos atuariais, para que sejam pagos ao mesmo trabalhador, durante o seu período de inatividade (SCHMÄHL, 1999). Por definição, na forma típica de um regime de capitalização inexistem transferências intergeracionais, uma vez que há realocação intertemporal de recursos para o mesmo indivíduo. Usualmente, neste regime, os benefícios são do tipo contribuição definida (CD), dado que seu valor só é conhecido ex-post, com base no montante contribuído e obtido para os ativos acumulados, definido pela taxa de juros $r$.

Nos regimes de repartição ocorre o oposto. As transferências de recursos intergeracionais são realizadas no mesmo período, das coortes de trabalhadores para as coortes de inativos, por meio de contribuições previdenciárias dos primeiros para o custeio dos benefícios do segundo grupo. Isto é feito a partir de um contrato social, representado pelo sistema previdenciário, em que as gerações ativas financiam os benefícios dos inativos (KUNÉ, 2001). Nesse regime, o retorno ocorre pela taxa de juros biológica i, conforme a designação feita no clássico artigo de Samuelson (1958), dada pela expressão $(1+i)=$ $(1+w)(1+n)$, em que $w$ é a taxa de crescimento dos salários e $n$ é a taxa de crescimento populacional. Nesse caso predomina o tipo benefício definido (BD), com o valor sendo dado ex-ante, em geral atrelado a alguma parcela do histórico de remunerações do trabalhador.

0 processo de envelhecimento populacional se dá em diferentes velocidades para diversos países, havendo tendência de ocorrer de maneira cada vez mais acelerada para os países com início tardio. Para os países em desenvolvimento, o processo é bem mais acelerado em relação ao ocorrido em países desenvolvidos (KINSELLA; GIST, 1995). Este processo de envelhecimento coloca sérias ameaças aos sistemas previdenciários de todos os países, particularmente para os regimes de repartição (HARPER, 2010; ISSA, 2016).

Por definição, havendo igualdade de despesas e receitas, em tais regimes não há acumulação ou desacumulação de ativos. Nesse caso, alterações em algumas variáveis relevantes afetam o equilíbrio do sistema. Por exemplo, a redução nas taxas de mortalidade 
em idades avançadas gera um incremento de longevidade. Dessa forma, há aumento no número de gerações coexistindo simultaneamente, o que provoca um incremento na razão de dependência de idosos (RDI), dada pela proporção de idosos em relação ao total da população. Esse efeito também aumenta o período de recebimento de benefícios, fazendo com que, em um dado período, o número de beneficiários e o montante despendido com benefícios aumentem. Dessa maneira, o processo de envelhecimento populacional resultante gera uma tendência endógena de desequilíbrio em regimes de repartição. É importante notar que este processo de envelhecimento também poderia ter outras causas, como a redução nas taxas de fecundidade.

Tal argumento pode ser ilustrado com o auxílio de modelo simplificado, apresentado na expressão (1). Nesta útil formulação, a cada período, $P$ é o valor do benefício médio, $t$ é a alíquota de contribuição, $W$ corresponde à renda média, $S$ refere-se ao número de trabalhadores e $N$ é o número de beneficiários (STEGĂROIU; STEGĂROIU, 2012). Supondo-se que o sistema seja equilibrado, as receitas (lado esquerdo da equação) são iguais aos dispêndios (lado direito). Isolando-se $P$ e fazendo a diferenciação total, chega-se à expressão (2). Dividindo-se esta equação por $P=t w S / N$, obtém-se a expressão (3).

$$
t_{t} W_{t} S_{t}=P_{t} N_{t}
$$

$\Delta P=\frac{W S}{N} \Delta t+\frac{t S}{N} \Delta W+\frac{t W}{N} \Delta S-\frac{t W S}{N^{2}} \Delta N$

$\frac{\Delta P}{P}=\frac{\Delta t}{t}+\frac{\Delta W}{W}+\frac{\Delta S}{S}-\frac{\Delta N}{N}$

A expressão (3) ajuda a entender a dinâmica de um regime de repartição, mostrando quais os determinantes da evolução relativa do benefício médio, dado o pressuposto de equilíbrio entre receitas e despesas. Dessa maneira, aumentos na alíquota contributiva, na renda média e no número de trabalhadores dão margem a incrementos no benefício. Por outro lado, crescimento no número de beneficiários colabora para a redução no benefício. Quaisquer variações fora da regra dinâmica apresentada na equação (3) levam o sistema para o desequilíbrio. Fica evidente que, diante do envelhecimento populacional (aumento em $N$ ), uma ou mais variáveis ( $t, W$ ou $S$ ) deverão ser majoradas para que o benefício possa ser mantido constante e o sistema não entre em desequilíbrio. Como uma elevação em $N$ deve, em geral, estar ligada a uma redução em $S$, e a renda média $W$ não é, a priori, uma variável de decisão, então a alternativa imediata para os formuladores de políticas previdenciárias seria aumentar a alíquota $t$ para preservar o equilíbrio financeiro do sistema. Uma segunda alternativa de política seria a redução no valor do benefício médio $P$. Esta argumentação simples, mas fundamental, será retomada na parte empírica deste trabalho.

Para regimes de capitalização, de modo diferente do exposto anteriormente, o ponto mais importante é o envelhecimento individual, pela própria natureza do regime. De forma esquemática, neste tipo de regime, os jovens adquirem ativos para custear sua própria 
aposentadoria. Já os idosos convertem os ativos anteriormente acumulados, vendendo-os e convertendo-os em anuidades. Períodos maiores de recebimento dos benefícios devem significar maior esforço de acumulação, ou benefícios de menor valor.

\section{Evidências empíricas}

A relação com a questão demográfica tem motivado parcela expressiva da literatura sobre previdência social. Por exemplo, durante o decênio 2007-2016, o International Social Security Review, o mais importante periódico da área de seguridade e previdência social, publicou 184 artigos, dos quais 35 (pouco mais de 19\%) abordaram temas diretamente ligados ao envelhecimento populacional. Holzmann (2013) é cético em relação a este fato e considera que esta expressiva produção contrasta com uma falta de percepção da sociedade e da classe política sobre a inevitabilidade de reformas que aumentem compulsoriamente a idade de aposentadoria ou que proporcionem incentivos para que os trabalhadores se aposentem mais tarde.

Entretanto, tal visão parece não se coadunar com uma extensa lista de países que empreenderam modificações em seus sistemas previdenciários nos últimos anos. Conforme mostram os estudos da $\operatorname{OECD}(2013,2015)$, todos os 34 países deste bloco realizaram reformas nos últimos anos, motivados principalmente pelas tensões demográficas. A medida mais adotada foi o aumento na idade de aposentadoria. Em menor grau foram feitas alterações na indexação dos benefícios, bem como elevações nas alíquotas contributivas. Por último, pouquíssimos países reduziram os valores nominais dos benefícios. Conforme sintetiza Harper (2010, p. 189), as reformas não devem se ater a um único aspecto. É importante integrar os mecanismos públicos e privados de transferências, repensar os aspectos de justiça intergeracional (pela divisão dos custos entre trabalhadores e aposentados), encorajar o aumento da responsabilidade individual pela aposentadoria e desenvolver modelos de proteção integrada de múltiplos pilares.

Há um volume significativo de contribuições sobre o tema. Uma das mais relevantes, com a qual este trabalho guarda similaridade, é a de Bongaarts (2004). 0 autor examina o efeito do envelhecimento populacional sobre os sistemas de previdência de sete países da OECD, com a premissa de que benefícios previdenciários e oferta de trabalho permanecerão estáveis, até 2060. Os resultados principais mostram grande elevação na relação aposentados/trabalhadores (o caso mais relevante é o da Itália, cujo indicador aumenta de cerca de 0,7 para 1,55) e nos gastos previdenciários em relação à renda (novamente a Itália é o caso mais agudo, com elevação $35 \%$ para $75 \%$, seguida pela França, que passa de menos de $30 \%$ para mais de $50 \%$ ).

No Líbano o envelhecimento populacional ocorre em taxas mais aceleradas do que os outros países da região. 0 trabalho de Jarmuzek e Nakhle (2016) mostra que, entre 2015 e 2050, as despesas somadas com os regimes de servidores públicos e de trabalhadores do setor privado vão triplicar, passando de 3,5\% para 10,5\%, sem a mesma contrapartida 
nas receitas. Já no caso do Uruguai, as despesas previdenciárias devem permanecer razoavelmente constantes em patamar inferior a 9\% do PIB (resultado de reformas anteriormente efetuadas), até a metade deste século, crescendo posteriormente para 9,5\% em 2050 e 13,4\% em 2100 (ROFMAN; APELLA, 2016). Empregando outros indicadores, Zeng (2011) chega a resultado similar para o caso chinês. 0 autor mostra que o déficit previdenciário (medido em proporção da massa de rendimentos) deve passar de cerca de 7,5\% em 2010 para 34,5\% em 2050, em um cenário com baixas taxas de mortalidade e de fecundidade.

Esta breve exposição trouxe evidências da relevância das mudanças demográficas para os regimes de repartição e as alternativas de políticas públicas. Países de características econômicas diferentes e em etapas diferenciadas da transição demográfica serão afetados, em horizontes mais próximos ou mais distantes. Diante desse quadro, o passo seguinte é quantificar tais mudanças para os países selecionados, com foco nos valores agregados de receitas, despesas e déficit.

\section{Países selecionados: características demográficas e dos sistemas previdenciários}

Nesta seção são descritas algumas características demográficas e econômicas, bem como apresentados os principais aspectos dos sistemas previdenciários de Brasil, Espanha e França. Em particular, o foco está no regime contributivo da previdência destas nações. $\mathrm{Na}$ taxonomia dos modelos multipilares apresentada por Holzmann e Hinz (2005), este corresponde ao pilar 1 , em que as contribuições compulsórias dos trabalhadores ao sistema público financiam, na forma de benefício definido, as aposentadorias e pensões dos inativos.

Como o objetivo deste trabalho é isolar os impactos das mudanças demográficas sobre o dispêndio com benefícios programáveis e sobre as receitas previdenciárias de países selecionados, com algum grau de similaridade entre si, o primeiro aspecto para a escolha foi a representatividade populacional. Foram considerados somente países com mais de 30 milhões de habitantes em 2014. 0 segundo aspecto é que estes países devem ter regimes de repartição, pelo fato de este arranjo ser mais suscetível aos efeitos do envelhecimento, conforme apresentado por extensa literatura, por exemplo, Schmähl (1990), Uhlenberg (2005) e Cipriani (2014). 0 terceiro aspecto foi o nível de dispêndio. França e Espanha são países classificados por Schwarz et al. (2014) como high-income generous spenders, característica compartilhada com o Brasil, para o dispêndio elevado.

O Brasil gastava com previdência social 13,1\% do seu PIB (dados de 2016). França e Espanha gastavam 13,8\% e 11,4\%, respectivamente (dados de 2013). São valores similares, mesmo tendo o Brasil valores de razão de dependência de idosos e índice de envelhecimento (IE) iniciais bastante inferiores (Tabela 2). E, como mostram os dados desta mesma tabela, o IE brasileiro será parecido com o francês em 2050 (152 em relação a 157) e com o espanhol em 2100 (239 em relação a 258). Dessa forma, é possível comparar o efeito do 
envelhecimento populacional sobre países que compartilham uma característica (o gasto elevado) e que em algum momento (2050 e 2100) terão estruturas demográficas similares.

Adicionalmente, os três países têm taxas brutas de reposição próximas, de acordo com a metodologia da OECD (2017). Nesta publicação, os valores das TRs para indivíduos de renda média de França, Brasil e Espanha são, respectivamente, 60,5\%, 69,5\% e 72,3\%. Desse modo, além de a questão agregada (vista pelo lado do dispêndio) ser similar, também há semelhança no que se refere à questão individual (vista pelo lado da taxa de reposição).

Finalmente, estes países devem ter empreendido alguma reforma previdenciária recentemente, seja ela mais radical, como aquelas realizadas pela Espanha (DÍAZ-GIMENEZ; DÍAS-SAAVEDRA, 2017), ou menos efetiva, como no caso francês (GUILLEMARD, 2016). Neste último país, a idade efetiva de aposentadoria pouco se alterou, característica negativa compartilhada com o Brasil.

\section{Características demográficas e econômicas}

A Tabela 1 traz alguns dados econômicos dos países selecionados: o Produto Interno Bruto (PIB) a valores de mercado e o PIB per capita.

Os três países selecionados passam por um processo de envelhecimento. A Tabela 2 apresenta quatro variáveis: número de idosos (65 anos e mais); população economicamente ativa (PEA) (15 a 64 anos); razão de dependência de idosos, dada pela divisão das duas variáveis anteriores; e o índice de envelhecimento, calculado pela relação entre o número de idosos (65 anos e mais) e o número de jovens ( 0 a 14 anos). São reportados os valores efetivamente verificados, desde 1950, e os valores previstos até 2100 .

TABELA 1

Produto Interno Bruto e PIB per capita

Brasil, Espanha e França - 2014

\begin{tabular}{|c|c|c|}
\hline Países & PIB (USD bilhões) & PIB per capita (USD) \\
\hline Brasil & $2.416,64$ & 11.727 \\
\hline Espanha & $1.381,34$ & 29.861 \\
\hline França & $2.829,19$ & 44.123 \\
\hline
\end{tabular}

Fonte: Banco Mundial e Organização Internacional do Trabalho.

O Brasil tem atualmente menor participação relativa de idosos na composição populacional quando comparado com Espanha e França, nações já consideradas demograficamente maduras. Entretanto, observa-se que o Brasil enfrentará rápido processo de envelhecimento, sendo estimado que a RDI brasileira, que em 2010 correspondia a 9,83\%, alcance $19,87 \%$ em 2030, 36,59\% em 2050 e $61,90 \%$ em 2100 . Este último valor é maior que o previsto para a França $(56,16 \%$ ) e pouco inferior aos $65,11 \%$ esperado para a Espanha. De forma análoga, o IE brasileiro, que em 2010 era bastante inferior aos dos outros dois países, atingirá $239,32 \%$ em 2100 , representando quase o mesmo valor espanhol (258,06\%) e bem mais que os $196,48 \%$ da França. 
TABELA 2

Idosos, população economicamente ativa (PEA), razão de dependência de idosos (RDI) e índice de envelhecimento

Brasil, Espanha e França - 1950-2100

\begin{tabular}{|c|c|c|c|c|c|c|c|c|c|c|c|c|}
\hline \multirow[b]{2}{*}{ Anos } & \multicolumn{4}{|c|}{ Brasil } & \multicolumn{4}{|c|}{ Espanha } & \multicolumn{4}{|c|}{ França } \\
\hline & $\begin{array}{c}\text { Idosos } \\
(65 \\
\text { anos e } \\
\text { mais) } \\
\text { (em } \\
\text { mil) }\end{array}$ & $\begin{array}{l}\text { PEA } \\
(15-64 \\
\text { anos) } \\
\text { (em } \\
\text { mil) }\end{array}$ & $\begin{array}{l}\text { RDI } \\
(\%)\end{array}$ & IE (\%) & $\begin{array}{c}\text { Idosos } \\
(65 \\
\text { anos e } \\
\text { mais) } \\
\text { (em mil) }\end{array}$ & $\begin{array}{c}\text { PEA } \\
\text { (15-64 } \\
\text { anos) } \\
\text { (em } \\
\text { mil) }\end{array}$ & $\begin{array}{l}\text { RDI } \\
\text { (\%) }\end{array}$ & IE (\%) & $\begin{array}{c}\text { Idosos } \\
(65 \\
\text { anos e } \\
\text { mais) } \\
\text { (em } \\
\text { mil) }\end{array}$ & $\begin{array}{c}\text { PEA } \\
(15-64 \\
\text { anos) } \\
\text { (em } \\
\text { mil) }\end{array}$ & $\begin{array}{l}\text { RDI } \\
\text { (\%) }\end{array}$ & IE (\%) \\
\hline 1950 & 1.606 & 29.937 & 5,36 & 7,16 & 2.028 & 18.605 & 10,90 & 27,27 & 4.772 & 27.621 & 17,28 & 50,31 \\
\hline 1960 & 2.275 & 38.790 & 5,87 & 7,24 & 2.492 & 19.629 & 12,70 & 29,92 & 5.315 & 28.504 & 18,65 & 44,12 \\
\hline 1970 & 3.284 & 51.908 & 6,33 & 8,05 & 3.256 & 21.129 & 15,41 & 34,14 & 6.523 & 31.735 & 20,55 & 51,83 \\
\hline 1980 & 4.562 & 70.766 & 6,45 & 9,73 & & & 17,51 & & & & 21,76 & 62,98 \\
\hline 1990 & 6.037 & 91.153 & 6,62 & 11,35 & 5.232 & 26.120 & 20,03 & 66,76 & 7.985 & 37.650 & 21,21 & 70,61 \\
\hline 2000 & 8.878 & 114.733 & 7,74 & 17,02 & 6.780 & 27.951 & 24,26 & 112,66 & 9.563 & 38.665 & 24,73 & 85,69 \\
\hline 2010 & 13.260 & 134.943 & 9,83 & 26,30 & 7.999 & 31.800 & 25,15 & 117,58 & 10.719 & 40.622 & 26,39 & 92,25 \\
\hline 2020 & 20.342 & 150.739 & 13,49 & 45,29 & 9.386 & 30.229 & 31,05 & 142,67 & 13.700 & 40.202 & 34,08 & 115,91 \\
\hline 2030 & 30.964 & 155.839 & 19,87 & 73,97 & 11.815 & 28.506 & 41,45 & 211,02 & 16.247 & 40.127 & 40,49 & 139,65 \\
\hline 2040 & 41.806 & 155.702 & 26,85 & 108,56 & 14.626 & 25.569 & 57,20 & 268,23 & 18.191 & 39.891 & 45,60 & 153,53 \\
\hline 2050 & 54.267 & 148.308 & 36,59 & 152,03 & 16.049 & 23.096 & 69,49 & 281,77 & 18.731 & 40.442 & 46,32 & 156,57 \\
\hline 2060 & 62.978 & 139.434 & 45,17 & 187,43 & 14.918 & 22.714 & 65,68 & 272,15 & 19.032 & 41.179 & 46,22 & 160,59 \\
\hline 2070 & 69.339 & 128.528 & 53,95 & 218,07 & 13.636 & 22.197 & 61,43 & 258,81 & 19.891 & 41.311 & 48,15 & 167,06 \\
\hline 2080 & 69.766 & 120.460 & 57,92 & 231,11 & 13.400 & 21.012 & 63,77 & 251,99 & 21.114 & 41.214 & 51,23 & 176,97 \\
\hline 2090 & 68.446 & 113.001 & 60,57 & 237,60 & 13.311 & 20.466 & 65,04 & 252,68 & 22.151 & 41.275 & 53,67 & 187,40 \\
\hline 2100 & 66.035 & 106.677 & 61,90 & 239,32 & 13.114 & 20.141 & 65,11 & 258,06 & 23.103 & 41.138 & 56,16 & 196,48 \\
\hline
\end{tabular}

Fonte: United Nations Population Division (2017).

\section{Descrição sucinta dos sistemas de previdência social}

É apresentada nesta seção uma breve descrição das principais características dos sistemas previdenciários dos países selecionados, com ênfase nos benefícios programáveis.

Brasil

A previdência social brasileira é dividida no Regime Geral de Previdência Social (RGPS) e nos Regimes Próprios de Previdência Social dos servidores públicos e dos militares (RPPS) (BRASIL, 1999). O RGPS é de caráter contributivo e de filiação obrigatória (BRASIL, 1988), sendo considerados segurados o empregado e o trabalhador avulso, o empregado doméstico, o contribuinte individual, os segurados especiais, os facultativos e microempreendedores individuais (BRASIL, 1999). Os benefícios previstos são: aposentadorias por invalidez, por idade, por tempo de contribuição e especial; auxílio-doença; salário-família; salário-maternidade; auxílio-acidente; pensão por morte; e auxílio-reclusão (BRASIL, 1999).

Em 2016 a condição de exigibilidade para as aposentadorias por idade era de 180 contribuições mensais (15 anos), com idade de 65 anos para homens e 60 anos para 
mulheres, idades reduzidas em cinco anos para os trabalhadores rurais (BRASIL, 1999). Para as aposentadorias por tempo de contribuição, há apenas um requisito de período contributivo de 35 anos para os homens e 30 anos para as mulheres (BRASIL, 1988). Para professores e mulheres, o período contributivo é reduzido em cinco anos.

No caso de morte do segurado, depois de transcorridas 18 contribuições, o cônjuge sobrevivente tem direito ao valor integral da aposentadoria que o segurado recebia quando da morte ou ao valor que o segurado teria direito em caso de aposentadoria por invalidez.

Em 2017, os salários de contribuição e de benefício tinham como valor máximo $\mathrm{R} \$ 5.531,38$. A alíquota de contribuição do empregado é variável com a renda (8\% até $R \$ 1.659,38,9 \%$ entre $R \$ 1.659,39$ e $R \$ 2.765,66$ e $11 \%$ entre $R \$ 2.765,67$ e $R \$ 5.531,31$ ). O empregador contribui com $20 \%$ do salário, sem limite máximo.

\section{Espanha}

O sistema previdenciário público espanhol é formado pelo sistema geral e por sistemas especiais que abrangem funcionários públicos, militares, autônomos, trabalhadores do mar e de minas de carvão. A alíquota contributiva é de $28,3 \%$, dos quais participam o trabalhador com 4,7\% e o empregador com $23,6 \%$, aplicáveis entre as faixas de EUR 735,00 e EUR 3.597,00 mensais. A arrecadação financia os benefícios de aposentadoria por idade e as pensões, além do auxílio-doença, maternidade, paternidade e acidentes de trabalho. 0 governo custeia integralmente os benefícios assistenciais.

Tem direito ao benefício de aposentadoria por idade aquele que completa 65 anos e dois meses com ao menos 15 anos de contribuições. Tem direito ao benefício integral quem contribuiu por 35 anos e seis meses (aumento gradativo de três meses por ano, até completar 38 anos e seis meses em 2027). O sistema prevê a possibilidade de early retirement quando o segurado com mais de 61 anos e dois meses (chegando a 65 em 2027) com ao menos 33 anos de contribuição está desempregado. Para o cálculo do benefício, consideram-se $50 \%$ dos rendimentos do segurado nos primeiros 15 anos de contribuição, aplicado pequeno percentual pelos $16^{\circ}$ e $17^{\circ}$ anos. 0 valor mínimo do benefício é EUR 632,90 ou EUR 780,90 se houver cônjuge dependente. 0 valor máximo do benefício é de EUR 2.554,49. São realizados 14 pagamentos anuais.

0 benefício de aposentadoria por idade pela assistência social destina-se às pessoas com mais de 65 anos em situação de necessidade, residentes na Espanha por pelo menos dez anos a partir dos 16 anos. 0 valor do benefício está entre EUR 91,48 e EUR 365,90. É elegível à pensão por morte o cônjuge que tenha sido casado por ao menos um ano, ou coabitado por ao menos dois anos, e o segurado ter contribuído em ao menos 500 dias dos cinco anos anteriores à morte e esta tiver decorrido de doença comum, ou se o segurado recebia ou estava elegível a benefício de aposentadoria por idade no momento da morte, ou tinha ao menos 15 anos de contribuição quando da morte. A pensão cessa quando ocorre novo casamento, podendo o benefício continuar sendo pago em algumas condições 
(renda, idade ou incapacidade). Em caso de morte acidental, não se exigem contribuições prévias. A base de cálculo do benefício são os valores recebidos pelo segurado nos 24 melhores meses nos últimos 15 anos antes do falecimento (mínimo de EUR 753 e máximo de EUR 3.597). O valor do benefício é de $52 \%$ da base de cálculo, ou $70 \%$ se houver filhos dependentes ou se a renda do sobrevivente é menor que níveis definidos pelo governo. Pessoas com até 21 anos (ou 25 nos se desempregadas ou se ganharem menos que um salário mínimo; ou ilimitado se incapaz) têm direito às pensões. 0 valor do benefício é de $20 \%$ da mesma base de cálculo das pensões por morte.

França

O sistema previdenciário público é composto, além do regime geral, por regimes especiais para trabalhadores de mineração, ferrovias, setores de utilidade pública e funcionários públicos, trabalhadores do mar e autônomos rurais e não rurais.

A alíquota de contribuição para a previdência básica é de 15,25\%, dos quais 6,8\% são de responsabilidade do trabalhador e $8,45 \%$ do empregador, para os benefícios por idade e alguns dos benefícios ao cônjuge sobrevivente. Para a pensão por morte, a alíquota é de $2 \%$, sendo que o trabalhador participa com $0,25 \%$ e o empregador com $1,75 \%$. 0 salário contributivo máximo é de EUR 3.129. 0 trabalhador ainda pode fazer aportes para complementar o valor do benefício, de $4,5 \%$ a $12,6 \%$, limitado de quatro a oito salários contributivos máximos. 0 governo pode subsidiar a seguridade social, mas não subsidia os benefícios complementares.

Tem direito ao early retirement o segurado com idade a partir de 61 anos e dois meses (pensão parcial). A full retirement age é obtida aos 65 anos. 0 beneficiário pode começar um novo trabalho, mas deve esperar ao menos seis meses para exercer a mesma atividade anterior à aposentadoria. Se o beneficiário continuar trabalhando depois de receber a aposentadoria, há um means test, que reduz o benefício para $30 \%$ a $70 \%$ do valor original.

0 valor do benefício é $50 \%$ do resultado do valor médio de remuneração dos 25 melhores anos para os nascidos após 1948, observando-se o máximo de EUR 3.129,00 mensais. O benefício mínimo é de EUR 7.547,00 anuais. Pode ser beneficiário de pensão por morte o cônjuge sobrevivente com ao menos 55 anos, ou incapaz (incluindo esposa divorciada que não se casou novamente). 0 valor do benefício é o equivalente a $54 \%$ do benefício recebido pelo falecido ou do benefício a que tinha direito. A pensão anual máxima é de EUR 10.137,96. Complemento ao benefício por filhos ocorre quando o sobrevivente teve três ou mais filhos (adicional de 10\% da aposentadoria).

\section{Procedimentos metodológicos}

Conforme descrito anteriormente, neste trabalho procura-se isolar e quantificar o efeito das mudanças demográficas sobre os sistemas previdenciários dos três países 
selecionados. Dado este objetivo, o desenho de pesquisa adotado considera constantes todas as variáveis não demográficas e que somente a estrutura demográfica sofrerá mudanças ao longo do tempo. A forma de calcular as variáveis econômicas por gênero e coorte pode ser considerada uma simplificação do método das componentes das coortes (O’NEILL et al., 2001). De forma esquemática, para cada ano, até 2100 , replicam-se as proporções de contribuintes e beneficiários, por grupo etário e sexo, verificadas no ano inicial. 0 mesmo é feito com os valores médios da renda (e, por conseguinte, das contribuições) e dos benefícios programáveis. Assim, a despesa total é calculada com base na agregação por faixa etária e sexo dos valores médios dos benefícios multiplicados pelo número de beneficiários. Para a receita, multiplica-se a renda média pela alíquota contributiva e pelo número de contribuintes.

De forma consistente, considerou-se que não haverá mudança nas condições de elegibilidade e nas regras de concessão dos benefícios ao longo do tempo. Este é um procedimento similar àquele realizado por Costanzi e Ansiliero (2017), que, no entanto, analisaram somente o caso brasileiro.

0 restante desta seção descreve as duas etapas do procedimento efetuado: projeção de contribuições; e projeção de despesas.

\section{Projeção de contribuições para benefícios programáveis}

A partir do ano inicial de 2014, para cada país, foram verificadas as proporções de contribuintes por grupo etário e sexo, supostas constantes ao longo do tempo, bem como imputada a renda média. Em seguida, foi calculado o valor médio de contribuição, obtido pela multiplicação das alíquotas contributivas aos salários, também por grupo etário e sexo. Estes valores foram então multiplicados pelo número de contribuintes esperado a cada ano (dados pela projeção populacional das Nações Unidas), resultando no valor total de contribuições esperadas. Posteriormente, calculou-se o percentual das contribuições atuais destinadas a pagamento de benefícios programáveis, com base nas informações dos institutos de previdência de cada país. Esta proporção observada foi aplicada ao valor total de contribuições esperadas, obtendo-se o montante das contribuições direcionado aos benefícios programáveis.

Para o cálculo dos valores de contribuições da Espanha, foram unificadas duas bases distintas do Instituto Nacional de Estatística (INE), já que a primeira base apresentava decis das faixas de valor de salário por sexo, e a segunda por grupos etários. No caso da França, informações sobre renda foram obtidas da Caisse Nationale d’Assurance Vieillesse (CNAV).

Para o caso do Brasil, considerando a base de quantidade de contribuintes empregados e valor das remunerações por sexo segundo as faixas de valor, divulgada pelo extinto Ministério do Trabalho e Previdência Social (MTPS), para a quantificação do valor de contribuição foi aplicada a alíquota contributiva paga pela empresa sobre o salário total, conforme a legislação previdenciária então vigente. 


\section{Projeção de despesas com benefícios programáveis}

A metodologia para a projeção de despesas é análoga à da projeção das contribuições. Verificou-se o percentual de beneficiários por grupo etário, sexo e por espécie de benefício programável, sendo este percentual suposto constante para as populações projetadas ao longo do tempo. Foi então calculado o valor médio do benefício, por grupo etário, sexo e espécie de benefício. Em seguida, o valor médio encontrado foi multiplicado pelo número esperado de beneficiários. Pela agregação das categorias foi obtido o dispêndio total esperado com benefícios programáveis até 2100 .

Para o caso brasileiro, os dados divulgados pelo extinto MTPS continham dados com idade e sexo ignorados. Estes foram distribuídos entre as demais células, conforme a proporção de cada grupo etário e sexo no total.

No Apêndice é apresentada uma descrição mais detalhada dos procedimentos efetuados para cada país. Os dados agregados de contribuições, benefícios e alíquotas também estão disponibilizados.

\section{Resultados}

Cenário base: contribuições, benefícios e déficit previdenciário

O processo de envelhecimento populacional implicará, na suposição de manutenção das atuais regras, maior quantidade de benefícios programáveis, conforme apresentado na Tabela 3. Este número cresce com maior impacto e de forma mais acelerada para o Brasil, que atualmente está em fase próxima ao final do bônus demográfico, do que para Espanha e França. Dessa maneira, o primeiro resultado é claro: dentre os países escolhidos, o Brasil é o que mais sofrerá com o envelhecimento populacional. Os valores apresentados para o Brasil são um pouco inferiores àqueles reportados por Tafner, Botelho e Erbisti (2014). Porém, deve ser lembrado que estes autores apresentam valores agregados para todos os benefícios e não somente para os programáveis, como ocorre no presente trabalho.

TABELA 3

Número esperado de benefícios programáveis Brasil, Espanha e França - 2016-2100

\begin{tabular}{ccrrrrr}
\hline Ano & Brasil & \multicolumn{1}{c}{$\Delta \%$} & \multicolumn{1}{c}{ Espanha } & \multicolumn{1}{c}{$\Delta \%$} & \multicolumn{1}{c}{ França } & \multicolumn{1}{c}{$\Delta \%$} \\
\hline 2016 & 23.782 .382 & - & 8.215 .556 & - & 14.385 .721 & - \\
2020 & 27.702 .058 & 16,48 & 8.831 .864 & 7,50 & 15.581 .332 & 8,31 \\
2030 & 38.949 .438 & 63,77 & 10.963 .979 & 33,45 & 18.082 .595 & 25,70 \\
2040 & 51.607 .390 & 117,00 & 13.424 .380 & 63,40 & 19.643 .870 & 36,55 \\
2050 & 64.214 .348 & 170,01 & 14.740 .287 & 79,42 & 20.323 .264 & 41,27 \\
2060 & 74.227 .658 & 212,11 & 14.199 .376 & 72,84 & 20.697 .203 & 43,87 \\
2070 & 80.720 .392 & 239,41 & 13.143 .823 & 59,99 & 21.737 .202 & 51,10 \\
2080 & 82.624 .017 & 247,42 & 12.641 .969 & 53,88 & 22.893 .573 & 59,14 \\
2090 & 81.933 .287 & 244,51 & 12.654 .729 & 54,03 & 23.866 .155 & 65,90 \\
2100 & 79.564 .781 & 234,55 & 12.641 .737 & 53,88 & 24.907 .245 & 73,14 \\
\hline
\end{tabular}

Fonte: Instituto Nacional de Estatística para a Espanha, Caisse Nationale d’Assurance Vieillesse para a França, Ministério do Trabalho e Previdência Social para o Brasil. Cálculos dos autores. 
Um maior número esperado de benefícios programáveis, ceteris paribus, trará como consequência o aumento do dispêndio. 0 Gráfico 1 apresenta a projeção dos valores totais das contribuições, dos benefícios programáveis e dos déficits para os países analisados no cenário base. Para facilitar as comparações, os valores foram convertidos para dólares, sendo utilizadas as cotações de EUR 1 = USD 0,898967 e R\$ 1 = USD 0,309615 (médias entre $17 / 08 / 2016$ e 14/11/2016).

Observa-se que, apesar de o Brasil ter estrutura etária mais jovem quando comparado com Espanha e França, o dispêndio atual dos três países com benefícios previdenciários programáveis é similar em 2016. Este é um retrato das distorções de nosso sistema previdenciário, particularmente devido à aposentadoria precoce por tempo de contribuição (TURRA; AFONSO, 2017), que implica um período de recebimento do benefício muito longo, com reflexo sobre o montante despendido. Até 2050 o gasto aumenta para os três países, principalmente para o Brasil (mais de 160\%), ao passo que o valor das contribuições se reduz, o que significa déficits esperados cada vez maiores. Para a Espanha há redução após 2050, caso oposto ao de Brasil e França. 0 crescimento das despesas, que ocorre de maneira acelerada, é o principal elemento da elevação do déficit, principalmente para Brasil e França. Note-se ainda que, em 2100, o incremento das despesas no caso brasileiro (215\%) é três vezes maior do que o da França (73\%) e quase sete vezes superior ao caso espanhol (31\%).

GRÁFICO 1

Valores de contribuições, benefícios programáveis e déficit previdenciário Brasil, Espanha e França - 2016-2100

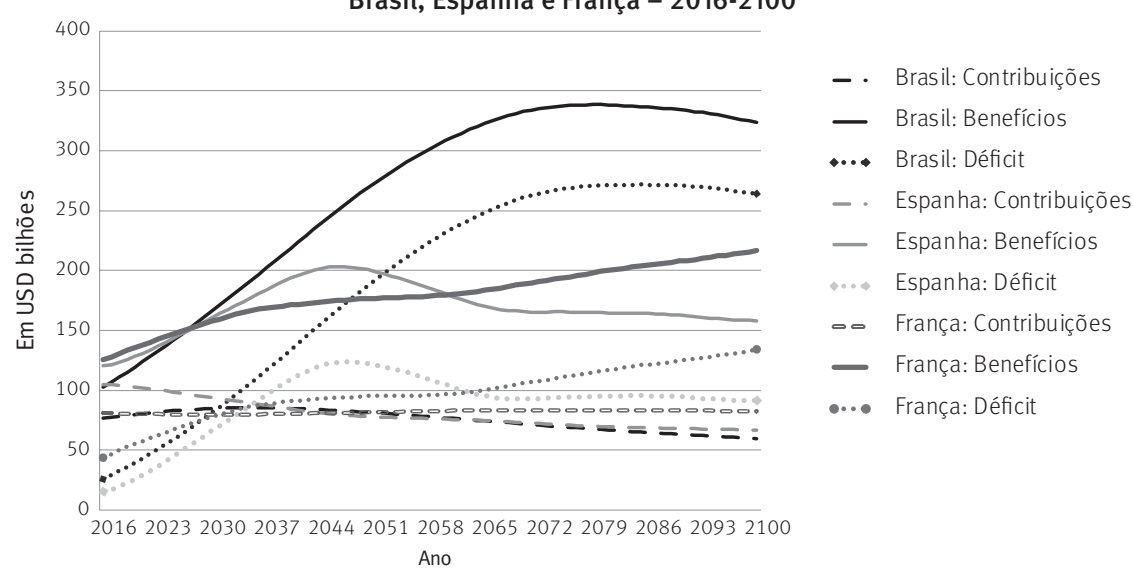

Fonte: Instituto Nacional de Estatística para a Espanha, Caisse Nationale d’Assurance Vieillesse para a França, Ministério do Trabalho e Previdência Social para o Brasil. Cálculos dos autores.

Em se mantendo as condições atuais, os três países sofrerão com o aumento do déficit previdenciário, mas o caso brasileiro é muito mais crítico do que o verificado para Espanha e França. As projeções revelam que, para o Brasil, há um déficit estimado em USD 81,55 bilhões em 2030 e USD 187,61 bilhões em 2050, apenas para benefícios programáveis. Este quadro é ainda mais preocupante, considerando-se que não estão computados os benefícios de risco e os assistenciais, componentes importantes do dispêndio dos sistemas previdenciários. 
É possível dividir o déficit com benefícios programáveis pelo número esperado de beneficiários, resultando no déficit anual com benefícios programáveis per capita, ilustrado pelo Gráfico 2. 0 déficit por beneficiário é menor para o Brasil do que para Espanha e França. Possivelmente este fato deve-se ao menor valor médio dos benefícios no Brasil, relembrando que para o primeiro país é esperado um crescimento muito maior no número de beneficiários do que para as duas últimas nações. Entretanto, os valores médios para o Brasil vão mais do que triplicar, passando de cerca de USD 1.100 para mais de USD 3.300. Ainda deve ser mencionado que a Espanha é o país com a maior redução projetada de contribuições, o que contribui para impulsionar o déficit, apesar do maior responsável por este ser o aumento dos gastos previdenciários. Certamente este quadro motivou uma série de reformas empreendidas em 2011 e 2013 (DÍAZ-GIMÉNEZ; DÍAZSAAVEDRA, 2016).

\section{GRÁFICO 2}

Déficit previdenciário per capita com benefícios programáveis Brasil, Espanha e França - 2016-2100

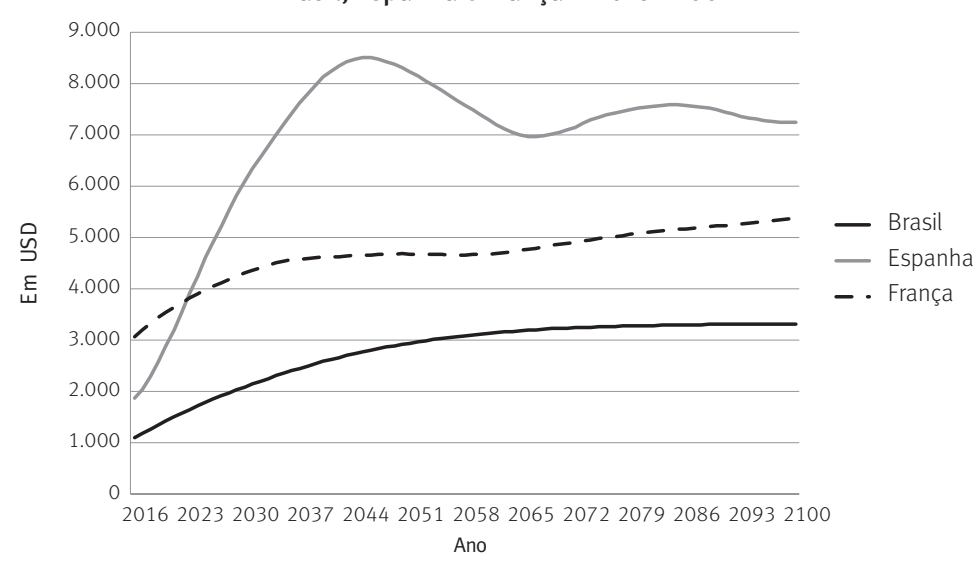

Fonte: Instituto Nacional de Estatística para a Espanha, Caisse Nationale d’Assurance Vieillesse para a França, Ministério do Trabalho e Previdência Social para o Brasil. Cálculos dos autores.

Na sequência, o Gráfico 3 ilustra o dispêndio esperado com benefícios programáveis como proporção do Produto Interno Bruto (PIB), suposto constante. Espera-se que países com maior RDI apresentem despesas previdenciárias mais elevadas. Entretanto, apesar de ser atualmente um país jovem, o Brasil tem proporção de gastos em relação ao PIB maior do que a França, e projeta-se que superará a Espanha em 2050, permanecendo assim por todo o período analisado. As despesas com benefícios programáveis passarão de menos de $6 \%$ para mais de $18 \%$ do PIB. Isto colocará fortes pressões sobre o restante do dispêndio público. Note-se que este dado é bastante similar àquele reportado por Jimeno, Rojas e Puente (2008), que calculam o dispêndio espanhol entre $16,0 \%$ e 19,6\% do PIB. 0 valor brasileiro superará o espanhol por volta de 2056. Já a França terá um crescimento mais discreto, passando de $5 \%$ para $9 \%$ do PIB. 
GRÁFICO 3

Proporção dos gastos com benefícios programáveis em relação ao PIB Brasil, Espanha e França - 2016-2100

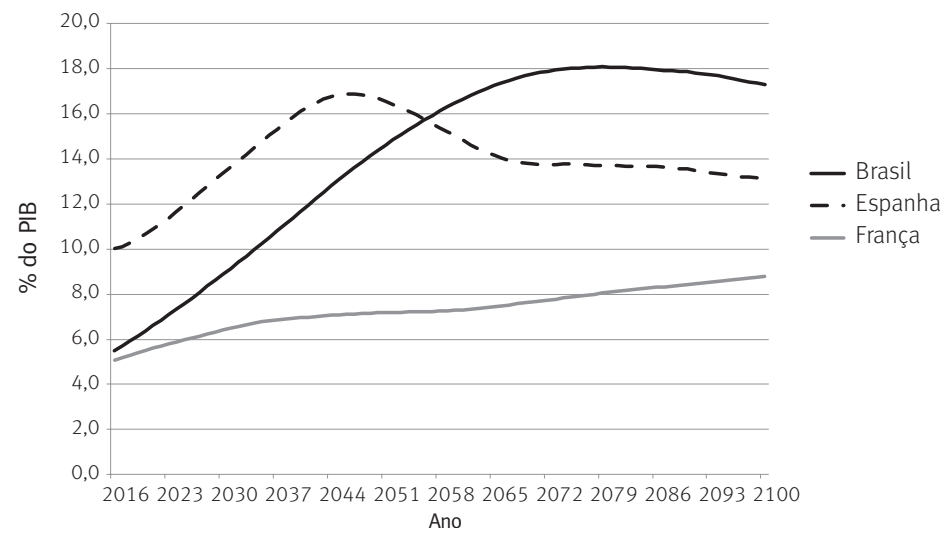

Fonte: Instituto Nacional de Estatística para a Espanha, Caisse Nationale d'Assurance Vieillesse para a França, Ministério do Trabalho e Previdência Social para o Brasil. Cálculos dos autores.

\section{Extensões}

Os resultados relatados na seção anterior mostram a necessidade imperiosa de empreender reformas previdenciárias, particularmente no Brasil, dada a tendência de incremento de grande magnitude no dispêndio e no déficit associado aos benefícios programáveis. Com base neste quadro, a questão que emerge é: o que pode ser feito para equacionar este déficit? As seções seguintes tentam responder a esta pergunta, calculando endogenamente dois parâmetros fundamentais de regimes de repartição, que podem ser alterados pelos formuladores de políticas: a alíquota de contribuição e o valor dos benefícios.

É importante explicitar algumas escolhas metodológicas subjacentes a estes exercícios. A primeira é o pressuposto de equilíbrio entre receitas oriundas de contribuições e despesas com benefícios em um regime de repartição. Isso significa que as duas extensões desejam verificar qual seria o esforço contributivo adicional (primeira extensão) ou a redução no valor do benefício (segunda extensão) para que não fosse necessário utilizar recursos oriundos de outras fontes para o financiamento da previdência. Assim, há uma suposição simplificadora implícita de equilíbrio nas contas da previdência. Também a escolha foi pautada pela característica dos dados empregados no paper, com informações agregadas por gênero e faixa etária. Dessa forma, os dois exercícios apresentados na sequência permitem alguns insights sobre os possíveis impactos oriundos de reformas tipicamente paramétricas (redução no valor do benefício e aumento na alíquota contributiva), mesmo sem o emprego de microdados ou recorrer à modificação no tempo mínimo de contribuição. Em particular, as diferenças entre as alíquotas de equilíbrio necessárias e as alíquotas verificadas atualmente, e entre os valores médios de benefícios calculados e existentes, são uma proxy do desequilíbrio dos sistemas previdenciários. 
Extensão 1: Alíquota de equilíbrio necessária

Faz-se aqui o cálculo de um indicador de uso recorrente na literatura previdenciária: a alíquota de equilíbrio necessária, definida como a alíquota teórica que deveria incidir sobre a renda dos trabalhadores para que o valor presente das contribuições fosse igual ao valor presente dos benefícios (AFONSO, 2016). Está implícita, nesta formulação, a suposição de que o sistema previdenciário deveria estar equilibrado a cada período. A expressão para a alíquota necessária $t_{t}$ para cada ano (equação 4) pode ser obtida por meio da manipulação da expressão (1), sendo a alíquota previdenciária $t$ a variável a ser calculada, em função da mudança na estrutura demográfica e da manutenção das demais variáveis. Exercício similar foi feito por Keuschnigg (2016) para analisar o caso do sistema de previdência da Suíça.

Deve ser notado que esta formulação pode ser interpretada como se houvesse um automatic balancing mechanism ( $A B M)$ no sistema previdenciário. Nos termos apresentados por Meneu et al. (2016), um mecanismo de ajustamento automático é uma regra que altera automaticamente o valor de algum parâmetro, quando alguma outra variável se modifica, visando manter a solvência do sistema. De acordo com Arbatli et al. (2016), Alemanha e Canadá são países que apresentam ABMs nas alíquotas de contribuição.

$t_{t}=\frac{P_{t} N_{t}}{W_{t} S_{t}}$

GRÁFICO 4

Alíquota de equilíbrio necessária para os benefícios programáveis Brasil, Espanha e França - 2016-2100

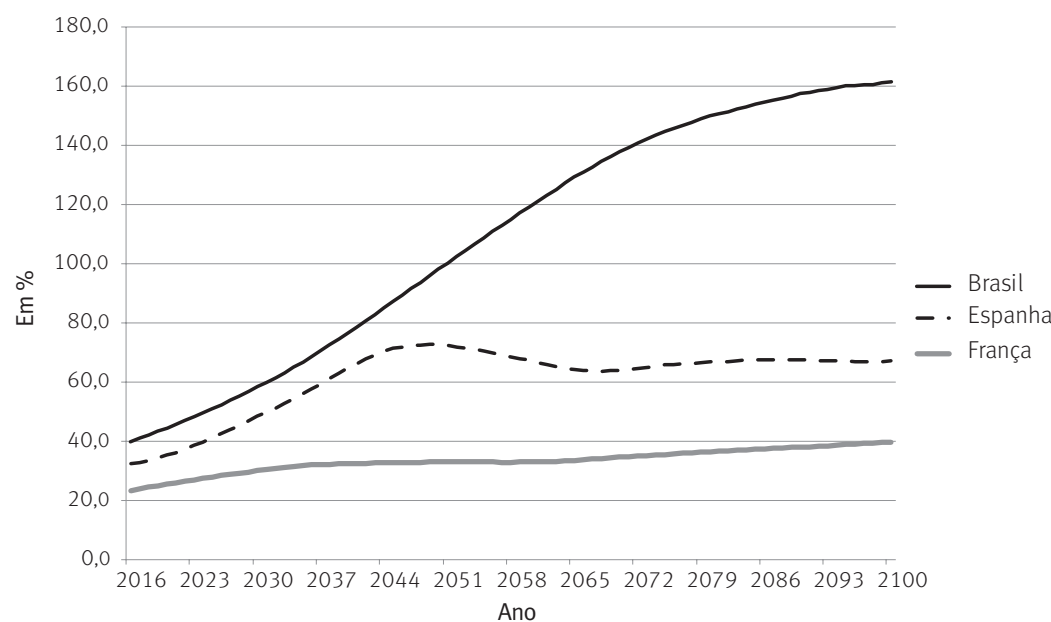

Fonte: Instituto Nacional de Estatística para a Espanha, Caisse Nationale d’Assurance Vieillesse para a França, Ministério do Trabalho e Previdência Social para o Brasil. Cálculos dos autores.

Para o Brasil, o Gráfico 4 mostra um crescimento acelerado e contínuo da alíquota necessária para uma situação de ausência de déficit com benefícios programáveis, considerando-se apenas as alterações previstas para as variáveis demográficas. A alíquota necessária 
em 2016 seria de 40\%. Este valor é um retrato que as alíquotas vigentes neste ano (28\%$31 \%)$ já são insuficientes. Se nada for feito, em 2050 esta alíquota ultrapassará absurdos $100 \%$ e, em 2100 , superará irreais $160 \%$. Este forte incremento é mais uma evidência da necessidade de se encontrar algum mecanismo para restabelecer a sustentabilidade do regime. Para os dois outros países, apesar de muito grave, o quadro é um pouco menos dramático, ficando pouco abaixo dos $70 \%$ para a Espanha e dos $40 \%$ para a França. Fica óbvio, no entanto, que nos casos brasileiro e espanhol mudanças de tal magnitude seriam absolutamente inviáveis. Entretanto, permitem explicitar o esforço contributivo que cada sociedade deveria fazer, caso deseje manter os benefícios nos níveis atuais.

Extensão 2: Benefício médio de equilíbrio

Dado o resultado da seção anterior, que mostrou uma alíquota de equilíbrio além dos patamares razoáveis, faz-se outra extensão. Este segundo exercício é o cálculo do benefício médio de equilíbrio. Na hipótese de manutenção das atuais alíquotas de contribuição, ceteris paribus, uma possibilidade para obtenção do equilíbrio entre contribuições e dispêndio com benefícios programáveis seria a alteração dos valores de benefícios, a cada ano $t$, em consonância com a equação (2). 0 Gráfico 5 traz os resultados do benefício médio de equilíbrio para que seja obtido tal equilíbrio. 0 cálculo feito também é uma aplicação da equação (1), rearranjando seus termos. Porém, neste caso a variável a ser calculada é o benefício médio $P$, dadas a mudança na estrutura demográfica e a manutenção das demais variáveis.

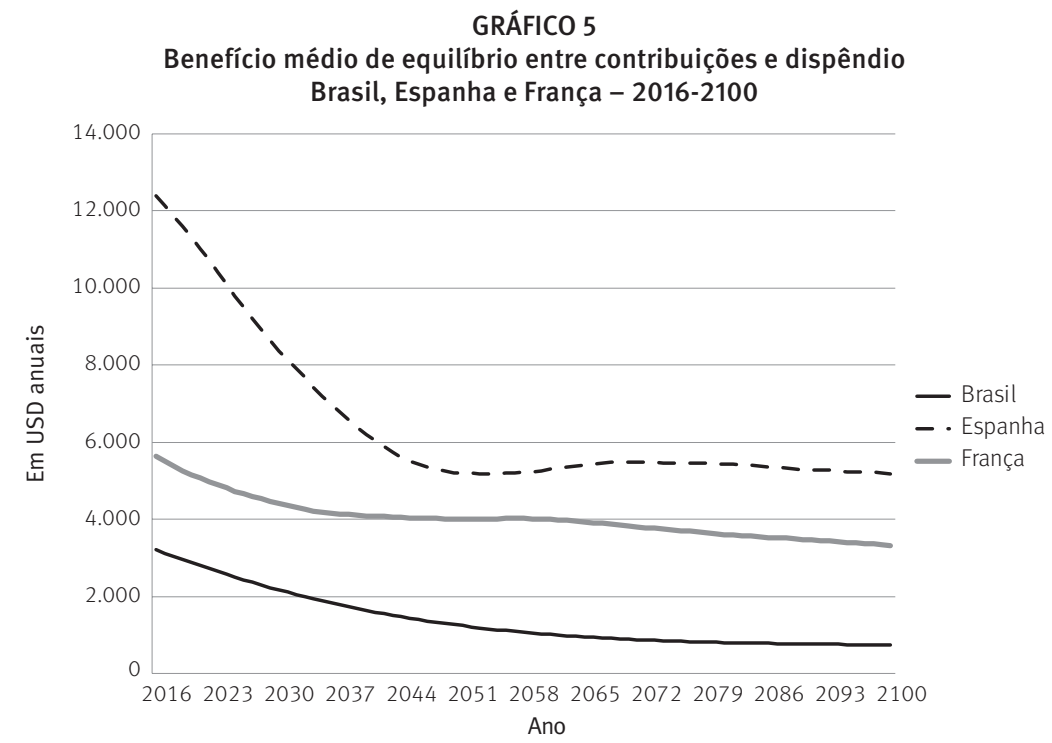

Fonte: Instituto Nacional de Estatística para a Espanha, Caisse Nationale d’Assurance Vieillesse para a França, Ministério do Trabalho e Previdência Social para o Brasil. Cálculos dos autores.

A diminuição mais expressiva em termos absolutos ocorreria para a Espanha, país em que o valor reduziria de USD 12.778 para USD 5.184, entre 2016 e 2100 . Nesse mesmo 
período, para o Brasil, o atual benefício de equilíbrio cairia de USD 3.218 para USD 751 e, na França, passaria de USD 5.640 para USD 3.317. A redução no caso brasileiro, em termos percentuais, é de $76,67 \%$. Mais uma vez, esta é uma medida indireta do desequilíbrio previdenciário, com o grande déficit resultante. Por outro lado, parece muito improvável que qualquer sociedade viesse a aceitar uma redução de tal magnitude nos benefícios, em nome do equilíbrio das contas da previdência.

\section{Conclusões}

Este trabalho procurou analisar os impactos do envelhecimento populacional sobre a previdência social de países com regime de repartição (Brasil, Espanha e França). Este tipo de análise comparativa encontra paralelo, por exemplo, em Börsch-Supan (1991) e Euwals et al. (2004). Os resultados aqui relatados apontam que, ceteris paribus, a maior proporção de idosos na população implica, principalmente, aumento de despesas e também menor arrecadação previdenciária. 0 resultado é um preocupante e insustentável déficit previdenciário. Estes desafios são maiores no caso de regimes de repartição, em que há transferência direta de contribuições da coorte trabalhadora para a coorte de inativos na forma de benefícios (KUNE, 2011).

Os resultados ainda mostram que o Brasil tem dispêndio total, com benefícios programáveis, superior a países com populações já envelhecidas. 0 acelerado envelhecimento que o país terá, já no curto prazo, implicará níveis de despesas que não poderão ser economicamente suportados. 0 déficit projetado acarreta a necessidade de urgentes reformas previdenciárias. A magnitude do desequilíbrio pode ser vista também, por outra ótica, com as alterações que seriam necessárias nas alíquotas ou nos valores dos benefícios, para que não houvesse déficits. Fica evidente que nenhum dos sistemas não atende aos requisitos de sustentabilidade, conforme preconizados na literatura (BROWN, 2008; MATTIL, 2006). Também fica claro que as transferências aos idosos, por meio dos benefícios previdenciários per capita, são bastante elevadas. Este resultado pode ser entendido como similar ao reportado por Turra, Queiroz e Rios-Neto (2011), que empregam a metodologia do NTA. Também se pode inferir que o Brasil não aproveitou de maneira adequada as oportunidades geradas pelo bônus demográfico, conforme preconizado por Lee e Mason (2010). Por este motivo, haverá muitas dificuldades para fazê-lo em contexto demográfico adverso, porém há longo tempo previsto (KAUFMANN; LEISERING, 1984).

O Brasil, apesar ter a população mais jovem do que Espanha e França, é, dentre estes países, o que possui a maior alíquota contributiva. 0 sistema previdenciário brasileiro apresenta diversos privilégios a alguns grupos específicos, como taxas de reposição altas, aposentadorias precoces, pensão por morte no valor integral da aposentadoria (AFONSO, 2016). Entretanto, isso ocorre mediante uma alta tributação sobre a renda, o que pode reduzir a oferta de mão de obra e desincentivar o trabalho formal. 
Para o caso espanhol, os resultados são similares, porém um pouco inferiores àqueles verificado na literatura. Para De La Fuente e Domenéch (2013), o valor do dispêndio previdenciário em 2046 será pouco inferior a 18\% do PIB. Aqui, o valor encontrado foi de 16,9\% do PIB neste mesmo ano. Já para Díaz-Gimenez e Días-Saavedra (2017), o dispêndio equivale a cerca de $21 \%$ do PIB no cenário incorporando os efeitos da reforma de 2010.

Os achados para o gasto previdenciário da França guardam similaridade com aqueles reportados por Blanchet, Le Minez e Marino (2017). Porém, neste caso, no cenário posterior às reformas de 2010, o gasto fica razoavelmente constante ao longo do tempo, na faixa de $12 \%$ do PIB. Já neste trabalho, o dispêndio sobe continuamente de maneira suave, mas sempre se mantendo inferior a $10 \%$. Ambos os resultados são significativamente inferiores aos valores obtidos por Chateau, Chojnicki e Magnani (2009), da ordem de $15 \%$ do PIB. Entretanto, deve ser lembrado que os cálculos destes autores referem-se ao cenário anterior às reformas empreendidas pela França.

No caso do Brasil, adotando metodologia similar à deste trabalho, Costanzi e Ansiliero (2017) encontram dispêndio com aposentadorias e pensões pouco superior a 16\% em 2050. Entretanto, deve ser notado que os autores fazem a projeção para o RGPS e o RPPS federal, diferentemente deste trabalho, em que é abordado apenas o primeiro regime. A projeção oficial do governo brasileiro para o RGPS (BRASIL, 2017) relata um gasto de $14,88 \%$ do PIB em 2050, valor inferior em cerca de 2 pontos percentuais ao que foi obtido aqui.

É importante mencionar as limitações do trabalho. A primeira delas é inerente à metodologia e à abordagem escolhida. Ao se considerarem todas as variáveis econômicas constantes (taxa de participação na PEA e parcela de beneficiários por faixa etária e sexo são as mais relevantes), todos os efeitos que não os do envelhecimento populacional não são levados em conta. Com isso, alterações, por exemplo, na taxa de formalização ou nas estruturas familiares não são captadas pelo artigo. Igualmente deve-se apontar que mudanças nas regras previdenciárias também não são analisadas neste trabalho. Dessa forma, eventuais medidas que os governos venham a adotar devem reduzir o dispêndio para níveis abaixo daqueles calculados.

As projeções aqui apresentadas mostram a necessidade de revisão das regras de concessão de benefícios e de cálculo de seu valor. Mudanças nos sistemas previdenciários foram realizadas nos três países. A França empreendeu várias reformas entre 2003 e 2014 (GUILLEMARD, 2016). A Espanha fez o mesmo em 2011 e 2013 (DÍAZ-GIMENEZ; DÍAS-SAAVEDRA, 2017). O Brasil também fez esforços dignos de nota, destacando-se as Emendas Constitucionais (EC) 20/1998, 41/2003 e 70/2012 (que trataram dos RPPS), a Lei $12.168 / 2012$, que criou a Funpresp, e a Lei 9.876/99 e o Decreto-Lei 3.265/99 (que criaram o fator previdenciário para o RGPS). Entretanto, em que pese a direção correta, a magnitude dos resultados não parece ter sido suficiente, dado o aumento previsto para as despesas, em relação ao PIB. Se medidas adicionais não forem adotadas no timing adequado, parcelas cada vez mais expressivas dos recursos públicos deverão ser direcionadas para o dispêndio previdenciário. Veja-se, por exemplo, o caso da Grécia, que 
protelou a adoção de medidas similares, implantou duras reformas e, mesmo assim, se vê na perspectiva de o dispêndio previdenciário continuar crescendo (SYMEONIDIS, 2017). Dada a elevação projetada para os gastos, parece pouco provável que haja a contrapartida na elevação das receitas oriunda do crescimento do PIB.

Por este motivo, parece que o cerne de eventuais mudanças deve ser o nível de dispêndio. De forma geral, são necessárias alterações sobre a idade mínima e a forma de cálculo dos benefícios, similares às que constam na Proposta de Emenda Constitucional 287, apresentada pelo governo no final de 2016 e cuja tramitação encontrava-se parada no Congresso no momento em que este texto era finalizado. Cabe ainda apontar que outras extensões também poderiam ser feitas, com a quantificação de reformas não paramétricas, em particular uma alteração radical, do regime de repartição para o regime de capitalização. Porém, a complexidade de tal tarefa está além do escopo deste trabalho e pode eventualmente ser realizada em outros artigos.

\section{Referências}

ACOSTA-ORMAECHEA, S.; ESPINOSA-VEGA, M. A.; WACHS, D. Demographic changes in Latin America - the good , the bad and... Washington, D.C.: International Monetary Fund, 2017 (IMF Working Paper, n. 17/94). Disponível em: 〈https://www.imf.org/en/Publications/WP/ Issues/2017/04/13/Demographic-Changes-in-Latin-America-The-Good-the-Bad-and-44836>.

AFONSO, L. E. Progressividade e aspectos distributivos na previdência social: uma análise com o emprego dos microdados dos registros administrativos do RGPS. Revista Brasileira de Economia, v. 70, n. 1, p. 3-30, 2016. Disponível em: 〈https://doi.org/10.5935/0034-7140.20160001〉.

ARBATLI, E. C.; FEHER, C.; REE, J. J. K.; SAITO, I.; SOTO, M. Automatic adjustment mechanisms in Asian pension systems? Washington, D.C.: International Monetary Fund, 2016 (IMF Working Paper, n. 16/242). Disponível em: 〈https://www.imf.org/ /media/Websites/IMF/imported-fulltext-pdf/external/pubs/ft/wp/2016/_wp16242.ashx>.

BARR, N.; DIAMOND, P. The economics of pensions. Oxford Review of Economic Policy, v. 22, n. 1, p. 15-39, 2006. Disponivel em: 〈https://doi.org/10.1093/oxrep/grj002〉.

BLANCHET, D.; LE MINEZ, S.; MARINO, A. Building and interpreting macro/micro estimates of accrued-to-date pension liabilities: French reforms as a case study. Review of Income and Wealth, v. 63, n. 1, p. 70-94, 2017. Disponivel em: 〈https://doi.org/10.1111/roiw.12207〉.

BONGAARTS, J. Population aging and the rising cost of public pensions. Population and Development Review, v. 30, n. 1, p. 1-23, 2004. Disponível em: 〈https://doi. org/10.1111/j.1728-4457.2004.00001.x>.

BÖRSCH-SUPAN, A. Aging population: problems and policy options in the US and Germany. Economic Policy, v. 6, n. 12, p. 103-139, 1991. Disponível em: 〈http://www.jstor.org/ stable/1344450>.

BRASIL. Presidência da República. Constituição da República Federativa do Brasil de 1988. Brasília, 1988.

Presidência da República Decreto n. 3.048, de 06 de maio de 1999. Aprova 0 Regulamento da Previdência Social, e dá outras providências. Brasília, 1999.

Secretaria de Previdência. Ministério da Fazenda. Projeções atuariais para o Regime 
Geral de Previdência Social - RGPS. Brasília, 2017. Disponível em: 〈https://www12.senado.leg.br/ orcamento/documentos/ldo/2018-1/elaboracao/projeto-de-lei/proposta-do-poder-executivo/ anexo-iv.6-2013-projecoes-atuariais-para-o-regime-geral-de-previdencia-social-2013-rgps-art.40-ss-2o-inciso-iii-da-lei-complementar-no-101-d).

BROWN, R. L. Designing a social security pension system. International Social Security Review, v. 61, n. 1, p. 61-79, 2008. Disponível em: 〈https://doi.org/10.1111/j.1468-246X.2007.00303.x〉.

CHATEAU, J.; CHOJNICKI, X.; MAGNANI, R. Disparities in pension systems and financial flows among European countries. Journal of Pension Economics and Finance, v. 8, n. 1, p. 1-33, 2009. Disponivel em: 〈https://doi.org/10.1017/S1474747208003569〉.

CIPRIANI, G. P. Population aging and PAYG pensions in the OLG model. Journal of Population Economics, v. 27, n. 1, p. 251-256, 2014. Disponível em: 〈https://doi.org/10.1007/s00148-013-0465-9〉.

COSTANZI, R. N.; ANSILIERO, G. Impacto fiscal da demografia na previdência social. Rio de Janeiro: Ipea, 2017 (Texto para Discussão, n. 2291). Disponível em: 〈http://www.ipea.gov.br/ portal/images/stories/PDFs/TDs/td_2291.pdf>.

DE LA FUENTE, A.; DOMENÉCH, R. The financial impact of Spanish pension reform: a quick estimate. Journal of Pension Economics and Finance, v. 12, n. 1, p. 111-137, 2013. Disponível em: 〈https://doi.org/10.1017/S1474747212000182〉.

DÍAZ-GIMENEZ, J.; DÍAS-SAAVEDRA, J. The future of Spanish pensions. Journal of Pension Economics and Finance, v. 16, n. 2, p. 233-265, 2017. Disponivel em: 〈https://doi.org/10.1017/ S1474747216000093>.

EUWALS, R.; EYMANN, A.; BÖRSCH-SUPAN, A. Who determines household savings for old age? Evidence from Dutch panel data. Journal of Economic Psychology, v. 25, n. 2, p. 195-211, 2004. Disponível em: 〈https://doi.org/10.1016/S0167-4870(02)00190-3〉.

FELDSTEIN, M.; LIEBMAN, J. B. Social security. In: AUERBACH, A. J.; FELDSTEIN, M. (Ed.). Handbook of public economics. Amsterdam: North-Holland, 2002. v. 4, p. 2245-2324. Disponível em: 〈https://doi.org/10.7208/chicago/9780226241890.003.0007〉.

GUILLEMARD, A.-M. France: working longer takes time, in spite of reforms to raise the retirement age. Australian Journal of Social Issues, v. 51, n. 2, p. 127-146, 2016. Disponivel em: 〈https://doi. org/10.1002/j.1839-4655.2016.tb00370.x>.

HARPER, S. The capacity of social security and health care institutions to adapt to an ageing world. International Social Security Review, v. 63, n. 3-4, p. 177-196, 2010. Disponivel em: <https://doi. org/10.1111/j.1468-246X.2010.01374.X>.

HOLZMANN, R. Global pension systems and their reform: worldwide drivers, trends and challenges. International Social Security Review, v. 66, n. 1213, p. 1-29, 2013. Disponível em: 〈https://doi.org/10.1111/issr.12007〉.

HOLZMANN, R.; HINZ, R. Old-age income support in the 21st century. 1. ed. Washington, D.C.: World Bank Publications, 2005. Disponivel em: 〈https://doi.org/10.1596/0-8213-6040-X〉.

ISSA - International Social Security Association. Ten global challenges for social security. Geneva, 2016. Disponivel em: 〈https://www.issa.int/en_GB/resources/all-publications?p_p_ id=displayfoldercontent_WAR_ISSA_Event_Documentsportlet_INSTANCE_EkBtOHHQ3c7r\&p_p_ lifecycle $=2 \&$ p_p_state $=$ normal\&p_p_mode $=$ view\&p_p_cacheability $=$ cacheLevelPage\&p_p_ col_id=column-1\&p_p_col_pos=1\&p_p_cos.

JARMUZEK, M.; NAKHLE, N. Sustainability and equity challenges: some arithmetic on Lebanon's pension system. Washington, D.C.: International Monetary Fund, 2016 (IMF Working Paper, n. 16/46). 
JIMENO, J. F.; ROJAS, J. A.; PUENTE, S. Modelling the impact of aging on social security expenditures. Economic Modelling, v. 25, n. 2, p. 201-224, 2008. Disponível em: 〈https://doi. org/10.1016/j.econmod.2007.04.015〉.

KAUFMANN, F.-X.; LEISERING, L. Demographic changes as a problem for social security systems. International Social Security Review, v. 37, n. 4, p. 388-409, 1984. Disponível em: 〈https://doi. org/10.1111/j.1468-246X.1984.tb00839.x>.

KEUSCHNIGG, C. Aging, taxes and pensions in Switzerland. St. Gallen: University of St. Gallen, 2016 (Discussion Paper, n. 2016-1). Disponivel em: 〈http://www1.vwa.unisg.ch/RePEc/usg/ econwp/EWP-1601.pdf〉.

KINSELLA, K.; GIST, Y. J. Older workers, retirement , and pensions. U.S. Department of Commerce, 1995.

KUNÉ, J. B. The controversy of funding versus pay-as-you-go: what remains of the debate? Geneva Papers on Risk and Insurance - Issues and Practice, v. 26, n. 3, p. 418-434, 2001. Disponível em: 〈https://doi.org/10.1111/1468-0440.00127〉.

LEE, R.; MASON, A. Fertility, human capital, and economic growth over the demographic transition. European Journal of Population, v. 26, n. 2, p. 159-182, 2010. Disponivel em: 〈https:// doi.org/10.1007/s10680-009-9186-x>.

MATTIL, B. Determining factors for sustainability and distributional effects of pension systems. Pension systems: sustainability and distributional effects in Germany and the United Kingdom. 1.t ed. Heidelberg: Physica-Verlag, 2006. p. 27-66.

MCCARTHY, K. F. World population shifts: boom or doom. Santa Monica, C.A.: RAND Corporation, 2001 (Serie RAND Documented Briefings).

MENEU, R.; DEVESA, E.; DEVESA, M.; DOMÍNGUEZ, I.; ENCINAS, B. Adjustment mechanisms and intergenerational actuarial neutrality in pension reforms. International Social Security Review, v. 69, n. 1, p. 87-107, 2016. Disponivel em: 〈https://doi.org/10.1111/issr.12096〉.

MILLER, T.; CASTANHEIRA, H. C. The fiscal impact of population aging in Brazil: 2005-2050. Revista Brasileira de Estudos de População, v. 30 (suplemento), p. S5-S23, 2013. Disponível em: 〈https://doi.org/10.1590/S0102-30982013000400002〉.

O'NEILL, B. C.; BALK, D.; BRICKMAN, M.; EZRA, M. A guide to global population projections. Demographic Research, v. 4, n. 8, p. 203-288, 2001. Disponivel em: 〈https://doi.org/10.4054/ DemRes.2001.4.8〉.

OECD. Pensions at a glance 2013: OECD and G20 indicators. 1. ed. Paris: OECD Publishing, 2013. Disponivel em: 〈https://doi.org/10.1787/pension_glance-2013-en〉.

Pensions at a glance 2015: OECD and G20 indicators. Paris: OECD Publishing, 2015. Disponivel em: 〈https://doi.org/10.1787/pension_glance-2015-en〉.

Pensions at a glance 2017. OECD and G20 indicators. Paris: OECD Publishing, 2017. Disponível em 〈https://doi.org/10.1787/pension_glance-2017-en〉.

OMRAN, A. R. The epidemiologic transition: a theory of the epidemiology of population change. Milbank Quarterly, v. 83, n. 4, p. 731-757, 2005. Disponivel em: 〈https://doi. org/10.1111/j.1468-0009.2005.00398.x>.

PAILLAT. P. Europe is ageing: causes, aspects and repercussions of demographic ageing. International Social Security Review, v. 29, n. 2, p. 152-166, 1976. Disponivel em: 〈https://doi. org/10.1111/j.1468-246X.1976.tb00948.x>.

ROFMAN, R.; APELLA, I. Social protection in a demographic transition. In: ROFMAN, R.; AMARANTE, V.; 
APELLA, I. (Ed.). Demographic change in Uruguay: economic opportunities and challenges. Washington, D.C.: International Bank for Reconstruction and Development / The World Bank, 2016.

SAMUELSON, P. A. An exact consumption-loan model of interest with or without the social contrivance of money. Journal of Political Economy, v. 66, n. 6, p. 467-482, 1958. Disponivel em: 〈https://doi.org/10.1086/258100〉.

SCHMÄHL, W. Demographic change and social security. Journal of Population Economics, v. 3, n. 3, p. 159-177, 1990. Disponível em: 〈https://doi.org/10.1007/BF00163073〉.

SCHMÄHL, W. Fundamental decisions for the reform of pension systems. International Social Security Review, v. 52, n. 3, p. 45-55, 1999. Disponível em: 〈https://doi.org/10.1111/1468246X.00045>.

SCHWARZ, A. M.; ARIAS, O. S.; ZVINIENE, A.; RUDOLPH, H. P.; ECKARDT, S.; KOETTL, J., ABELS, M. The inverting pyramid: pension systems facing demographic challenges in Europe and Central Asia. 1. ed. Washington, D.C.: The World Bank, 2014. Disponivel em: 〈https://doi.org/10.1596/9780-8213-9908-8>.

STEGĂROIU, C.-E.; STEGĂROIU, V. Public pension funds management type: pay as you go (PAYG). African Journal of Business Management, v. 6, n. 30, p. 8775-8780, 2012. Disponível em: 〈https:// doi.org/10.5897/AJBM11.2708>.

SYMEONIDIS, G. Forging a new, solid social security system for Greece: The NTS proposal. In: PENSION BENEFITS AND SOCIAL SECURITY (PBSS) COLLOQUIUM. Proceedings... Cancún: International Actuarial Association (IAA), 2017. Disponivel em: 〈http://actuaries.org/cancun2017/ Papers/37. Georgios Symeonidis_Paper.pdf〉.

TAFNER, P.; BOTELHO, C.; ERBISTI, R. Transição demográfica e o impacto fiscal na previdência brasileira. In: CAMARANO, A. A. (Ed.). Novo regime demográfico: uma nova relação entre população e desenvolvimento? 1. ed. Rio de Janeiro: Ipea, 2014. p. 539-570.

TURRA, C. M.; AFONSO, L. E. A consolidação da Previdência Social desde 1988 e seu futuro em um país em envelhecimento. In: MENDES, G.; PAIVA, P. (Ed.). Políticas públicas no Brasil: uma abordagem institucional. 1. ed. São Paulo: Saraiva, 2017. p. 317-350.

TURRA, C. M.; QUEIROZ, B. L.; RIOS-NETO, E. L. G. Idiosyncrasies of intergenerational transfers in Brazil. In: LEE, R.; MASON, A. (Ed.). Population aging and the generational economy: a global perspective. 1. ed. Cheltenham: Edward Elgar, 2011. p. 394-407. Disponível em: 〈http://idl-bnc. idrc.ca/dspace/bitstream/10625/47092/1/IDL-47092.pdf〉.

UHLENBERG, P. Demography of aging. In: POSTON, D. L.; MICKLIN, M. (Ed.). Handbook of population. New York: Springer, 2005. p. 143-167.

VAUGHAN, E. J.; VAUGHAN, T. M. Fundamentals of risk and insurance. 10. ed. New York: Wiley, 2008.

ZENG, Y. Effects of demographic and retirement-age policies on future pension deficits, with an application to China. Population and Development Review, v. 37, n.3, p. 553-569, 2011. Disponivel em: 〈https://doi.org/10.1111/j.1728-4457.2011.00434.x〉.

\section{Sobre os autores}

Lucas Campos Amaro é formado em Ciências Atuariais pela Faculdade de Economia, Administração e Contabilidade da Universidade de São Paulo (FEA/USP) e em Direito pela Universidade Paulista (Unip). Analista de resseguro da Chubb Seguros Brasil S.A. 
Luís Eduardo Afonso é livre-docente pela Faculdade de Economia e Administração da Universidade de São Paulo (FEA/USP). Professor associado da FEA/USP. Bolsista de produtividade PQ 2 do CNPq.

\title{
Endereço para correspondência
}

\author{
Lucas Campos Amaro \\ Avenida General Ataliba Leonel, 789 \\ 02033-000 - São Paulo-SP, Brasil \\ Luís Eduardo Afonso \\ Avenida Professor Luciano Gualberto 908, prédio FEA 3, sala 215 \\ 05508-010 - São Paulo-SP, Brasil
}

\begin{abstract}
What are the effects of population aging on pension systems of Brazil, Spain and France?
\end{abstract}

The aim of this study is to analyze the impacts of population aging on pay-as-you-go pension schemes in three countries: Brazil, Spain and France. Benefits and contributions are calculated based on current rules and population projections by sex and age group, up until 2100. From 2016 to 2100 , the number of old-age benefits in the three countries is expected to increase by $235 \%, 54 \%$ and $73 \%$. By 2050 , ceteris paribus, the Brazilian deficit will amount to USD 188 billion, reaching USD 260 billion in 2100. For France and Spain figures will be USD 134 billion and USD 92 billion. In 2100, the Spanish per capita deficit will be the highest: USD 7,200, against USD 5,400 (France) and USD 3300 (Brazil). Two additional exercises are included. The first is the calculation of the Necessary Contribution Rate. By 2016 Brazil's rate should already be at $40 \%$. For the other countries, the rates should be 23\% (France) and 32\% (Spain). In 2050, unless some action is taken, the Brazilian rate will surpass an absurd $100 \%$, and by 2100 , an unreal $160 \%$. The second exercise was the calculation of the Average Balance Benefit. For Spain, there would be a reduction of USD 884 per month to USD 372 by 2050 . For Brazil, the current balance benefit of USD 248 would be reduced, by 2050, to USD 98. Reduction in Brazil (60\%) is almost the same as in Spain (58\%). The results provide evidence of the need for pension reforms due to aging.

Keywords: Aging. Pension system. Pay-as-you-go pension system.

\section{Resumen}

¿Cuáles son los efectos del envejecimiento poblacional en los sistemas de pensiones de Brasil, España y Francia?

El objetivo del trabajo es analizar los impactos del envejecimiento poblacional sobre los regímenes previsionales de reparto de tres países: Brasil, España y Francia. Los beneficios y las contribuciones se calculan sobre la base de las normas actuales y las proyecciones de población por sexo y grupo de edad hasta 2100. De 2016 a 2100 el número de beneficios programables en los tres países debería aumentar 235\%, 54\% y 73\%, respectivamente. En 2050, ceteris paribus, el déficit brasileño será de USD 188.000.000.000 y alcanzaría los USD 260.000.000.000 en 2100. Para Francia y España los valores serán USD 134.000.000.000 y USD 92.000.000.000. En 2100 el déficit per capita español será el más elevado: USD 7200, contra USD 5400 (Francia) y 
USD 3300 (Brasil). Se hacen en este trabajo dos ejercicios adicionales: el primero es el cálculo de la alícuota de contribución necesaria de equilibrio. En 2016 la alícuota de Brasil ya debería ser del 40\%. Para los demás países, las alícuotas deberían ser del 23\% (Francia) y del 32\% (España). En 2050, si no cambiara nada, la alícuota brasileña superará el absurdo 100\% y en 2100 superará el irreal $160 \%$. El segundo ejercicio es el cálculo del beneficio medio de equilibrio. Para España habría una reducción de USD 884 mensuales a USD 372 en 2050. Para Brasil, el actual beneficio de equilibrio de USD 248 se reduciría en 2050 a USD 98. La reducción en Brasil (60\%) es prácticamente igual a la de España (58\%). Los resultados proporcionan evidencias sobre la necesidad de reformas previsionales debido al envejecimiento.

Palabras clave: Envejecimiento. Regímenes previsionales. Régimen de reparto.

Recebido para publicação em 05/11/2017

Aceito para publicação em 22/05/2018

\section{APÊNDICE}

\section{Procedimentos metodológicos para cálculo das contribuições e benefícios}

A seguir são apresentados os procedimentos empregados para o cálculo das contribuições e benefícios para Brasil, França e Espanha. Para cada país, a primeira parte da descrição trata das contribuições e, a segunda, dos benefícios. Para cada parte, inicialmente abordam-se as quantidades e, na sequência, os valores.

1. Brasil

\subsection{Contribuições}

1.1.1. Número esperado de contribuintes por sexo e grupo etário a cada ano

- Foram obtidos os dados de projeção populacional anual por idade e sexo, até 2100, divulgados pela ONU.

- A população foi agregada por grupos etários, em faixas de cinco anos: 20 a 24 anos, 25 a 29 anos e assim sucessivamente, até a faixa de 65 a 69 anos. As faixas iniciais e finais são diferentes, englobando todos com idade até 19 anos, e com idade igual ou superior a 70 anos, respectivamente.

- Foi obtido no site do extinto Ministério do Trabalho e Previdência Social (MTPS) o número de contribuintes por grupo etário e sexo para 2014. Os valores que constavam como ignorados foram alocados nas categorias de idade e sexo, conforme as proporções dos contribuintes.

- As proporções de contribuintes por sexo e grupo etário foram aplicadas sobre a projeção populacional das Nações Unidas, resultando no número esperado de contribuintes a cada ano, por sexo e grupo etário, até 2100.

\subsubsection{Valor esperado das contribuições por sexo e grupo etário a cada ano}

- Foram obtidos no site do extinto MTPS os valores das remunerações anuais por grupo etário e sexo. Os valores que constavam como ignorados foram alocados nas categorias de idade e sexo conforme as proporções dos valores classificados.

- Estes valores foram divididos pelo número de contribuintes, por grupo etário e sexo, resultando na renda anual destas categorias de análise. 
- Os valores das contribuições anuais por grupo etário e sexo foram calculados multiplicando a renda média pelas alíquotas de contribuição do empregador (20\%) e do empregado ( $8 \%$ a $11 \%$ ), observando-se o teto previdenciário para a parte do empregado.

- O montante esperado de contribuições foi encontrado multiplicando o número de contribuintes esperado a cada ano por grupo etário e sexo por sua contribuição anual média, e posteriormente fazendo-se a soma de todas as categorias até 2100 .

- Em 2014, conforme informações do Anuário Estatístico da Previdência Social, 86,6\% das contribuições foram destinadas ao INSS (o restante se direciona ao sistema $\mathrm{S}$ e demais despesas legais). Esta proporção foi utilizada para ajustar o valor das contribuições destinado ao custeio dos benefícios.

\subsection{Benefícios}

1.2.1. Número médio de beneficiários e valores esperados por sexo e grupo etário a cada ano

- Foram obtidas no Anuário Estatístico da Previdência Social 2014 as quantidades de benefícios por espécie, sexo e grupo etário.

- O dispêndio total foi dividido pela quantidade de benefícios, obtendo-se os valores por espécie, grupo etário e sexo.

- Com base no número de benefícios e nos dados populacionais da ONU, foram obtidas as proporções de benefícios por grupo etário e sexo.

- Estas proporções de benefícios e seus valores médios em 2014 foram aplicados às projeções da ONU, para calcular o número esperado de benefícios e seus valores até 2100.

- Os valores por grupo etário e sexo foram agregados para obter o total de beneficiários e o dispêndio total até 2100.

2. França

\subsection{Contribuições}

\subsubsection{Número esperado de contribuintes por sexo e grupo etário a cada ano}

- Foram obtidos os dados de projeção populacional anual por idade e sexo, até 2100, divulgados pela ONU.

- Do site da Caisse Nationale d'Assurance Vieillesse (CNAV) foram obtidas as quantidades de contribuintes, por sexo e ano de nascimento. Isso permitiu calcular as idades destes grupos de contribuintes.

- O número de contribuintes foi dividido pela população (por sexo e idade), encontrando-se a proporção de contribuintes por sexo e idade.

- As proporções de contribuintes por sexo e idade foram aplicadas à projeção populacional da ONU, a cada ano até 2100 , resultando no número de contribuintes esperado por grupo etário e sexo.

2.2.1. Valores esperados das contribuições por sexo e grupo etário a cada ano

- Do site da CNAV foi obtido o número de contribuintes por idade e sexo.

- O montante de contribuições a cada ano foi calculado multiplicando o número de contribuintes esperado a cada ano, por sexo e idade, pela renda média e pela 
alíquota contributiva dos trabalhadores. Estes valores foram posteriormente agregados para se chegar à receita total a cada ano.

- Considerou-se, conforme informações da CNAV, que $8 \%$ da arrecadação é destinada aos benefícios de risco. Esta proporção foi descontada dos valores de receita calculados.

\subsection{Benefícios}

2.2.1. Número esperado de beneficiários por sexo e grupo etário a cada ano

- Do site da CNAV foram obtidas as quantidades de beneficiários, por sexo e idade.

- Estas quantidades foram divididas pela população (por sexo e idade), gerando as proporções de beneficiários, também por sexo e idade.

- Estas proporções foram aplicadas à projeção populacional da ONU, a cada ano até 2100 , encontrando-se o número de beneficiários esperado, por sexo e idade.

- Do site da CNAV foram extraídos os valores médios de benefícios por sexo.

- O número esperado de beneficiários por sexo e idade foi multiplicado pelos valores médios, gerando-se os valores a cada ano, até 2100.

\section{Espanha}

\subsection{Contribuições}

3.1.1. Número médio esperado de contribuintes por sexo e grupo etário a cada ano

- Foram obtidos os dados de projeção populacional anual por idade e sexo, até 2100, divulgados pela ONU.

- A população foi agregada por grupos etários, em faixas de cinco anos: 0 a 4 anos, 5 a 9 anos e assim sucessivamente, até a faixa de 80 a 84 anos. A última faixa é diferente, com todos com idade igual ou superior a 85 anos.

- Do site da previdência social foram extraídos os números de contribuintes por grupo etário e sexo.

- O número de contribuintes foi dividido pela população (por sexo e grupo etário), encontrando-se a proporção de contribuintes por sexo e grupo etário.

- As proporções de contribuintes por sexo e grupo etário foram aplicadas sobre a projeção populacional das Nações Unidas, resultando no número esperado de contribuintes a cada ano, por sexo e grupo etário, até 2100 .

\subsubsection{Valores esperados das contribuições por sexo e grupo etário a cada ano}

- Foram extraídas do site do Instituto Nacional de Estadística duas distribuições dos rendimentos, por faixa de valores e por sexo.

- Estas proporções foram aplicadas à projeção de contribuintes esperados para o ano de 2016, por sexo, e posteriormente por grupo etário. Com este procedimento foram calculados os números esperados de contribuintes por sexo e faixa etária, por faixa de renda.

- O montante de contribuições a cada ano foi calculado multiplicando o número de contribuintes esperado a cada ano, por sexo e idade, pela renda média e pela alíquota contributiva dos trabalhadores. Estes valores são posteriormente agregados para se chegar à receita total a cada ano. 
- Considerou-se, conforme informações do Ministério do Emprego e Seguridade Social, que $14,43 \%$ da arrecadação é destinada aos benefícios de risco. Esta proporção foi descontada dos valores de receita calculados.

\subsection{Benefícios}

3.2.1. Número esperado de beneficiários por sexo e grupo etário a cada ano

- As quantidades de benefícios, por espécie, sexo e grupo etário foram obtidas do Ministério do Emprego e Seguridade Social.

- Estas quantidades foram divididas pela população (por sexo e grupo etário), gerando as proporções de beneficiários, também por sexo, grupo etário e benefício.

- As proporções de contribuintes por sexo e grupo etário foram aplicadas sobre a projeção populacional das Nações Unidas, resultando no número de esperado de contribuintes a cada ano, por sexo e grupo etário, até 2100.

3.2.2. Número médio de beneficiários e valores esperados por sexo e grupo etário a cada ano

- No site do Ministério do Emprego e Seguridade Social da Espanha foram obtidos os valores médios de benefícios por tipo de benefício, sexo e grupo etário.

- O número esperado de beneficiários por sexo e idade foi multiplicado pelos valores médios, gerando-se os valores a cada ano, até 2100. 